\title{
Facial pain due to calcification in periodontoid tissue: Crowned dens syndrome
}

\author{
Chungnam National University Hospital, \\ Department of Anaesthesiology \& Pain Medicine, Daejeon, Korea. \\ JH Park, YJ Kim, YK Ko, YH Kim.
}

\section{INTRODUCTION}

Crowned dens syndrome (CDS) is a cause of neck pain characterized by calcium deposition in the periodontoid tissues. Clinical features of the syndrome are acute onset of neck pain and headache with fever.

Computed tomographic (CT) imaging is necessary for diagnosis. The prognosis of CDS is excellent. Symptoms disappear within several weeks and calcifications may be absorbed. We report a case of CDS with acute onset of severe neck pain, facial pain, and pharyngeal pain provoked by swallowing.

\section{CASE}

A 48-year-old woman presented to our pain clinic reporting right neck and right facial and pharyngeal pain with acute onset one week earlier. There was no history of trauma or medical illness. Six days earlier, she had been referred to a general hospital for treatment owing to fever and elevated inflammatory markers on tests performed at a local clinic.

When the patient first visited our clinic, her blood pressure was $115 / 62 \mathrm{mmHg}$, heart rate was $72 / \mathrm{min}$, and body temperature was $37.9^{\circ} \mathrm{C}$. She reported neck pain and facial and pharyngeal pain characterized as electric-like shooting, prickling, and burning pain aggravated by swallowing. She had no sensory changes or motor weakness. Under the suspicion of glossopharyngeal neuralgia, the patient was given a right glossopharyngeal nerve block with $1 \%$ lidocaine $50 \mathrm{mg}$ and betamethasone $2 \mathrm{mg}$. She also received oral gabapentin $900 \mathrm{mg}$ per day, a combination of tramadol $18.75 \mathrm{mg} /$ acetaminophen $162.5 \mathrm{mg}$ twice a day, and nortriptyline $5 \mathrm{mg}$ at night. For differential diagnosis with tumors or anatomical abnormalities, facial CT was planned, with follow-up one week later.

At the second visit one week later, facial CT showed a $1.3 \mathrm{~cm}$ calcified mass near the odontoid process and right $\mathrm{C} 1$ 2 facet joint (Fig. 1).
The diagnosis of CDS was made with radiologic findings of periodontoid calcification and clinical findings of acute onset of severe neck pain with fever. Cervical magnetic resonance imaging (MRI) was performed to confirm involvement of the nerve root and thecal sac, and to rule out malignancies. Cervical MRI showed a T2-dark signal intensity calcified mass, $1.3 \mathrm{~cm}$, near the right $\mathrm{C} 1-2$ facet joint, with compression of the right $\mathrm{C} 2$ nerve root and thecal sac (Fig. 2).

At that time, the patient reported an improvement in pain of 80 $90 \%$ since the glossopharyngeal nerve block, and she had no fever. Accordingly, no additional blood tests were performed. However, the right occipital pain persisted. Occipital compartment block was therefore performed with $1 \%$ lidocaine $50 \mathrm{mg}$ and betamethasone $2 \mathrm{mg}$.

At the third visit a week later, the occipital pain was resolved. The patient was able to continue pain-free without medication, with no further sequelae.
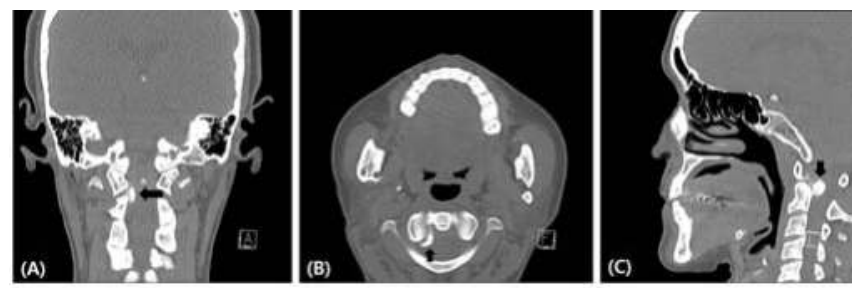

Figure 1. Coronal (A), axial (B) and sagittal (C) CT scan. Arrow: calcified mass in right posterolateral aspect of odontoid process at level of $\mathrm{C} 1-2$.
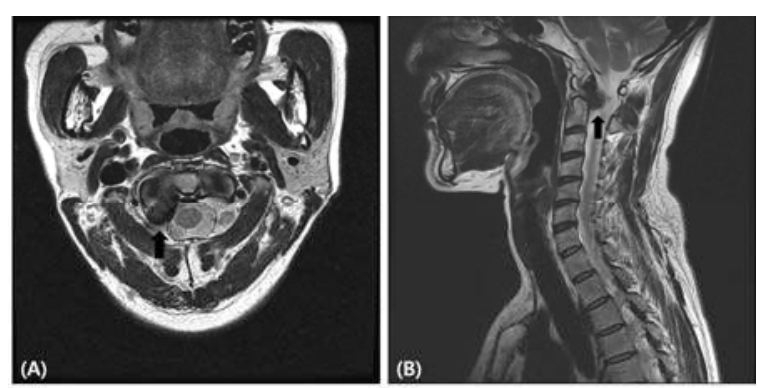

Figure 2. Axial (A) and sagittal (B) T2 MRI. Arrow: T2-dark signal intensity calcified mass, $1.3 \mathrm{~cm}$, near right $\mathrm{C} 1-2$ facet joint, with compression of right $\mathrm{C} 2$ nerve root and thecal sac. 